\title{
LIVESTOCK PRODUCERS KNOWLEDGE OF TECHNICAL RECOMMENDATIONS FOR THE CARE OF THE SUCKING CALVES AND APPROPRIATE EXTENSION COMMUNICATION METHODS FOR THEM IN KAFRELSHEIKH GOVERNORATE Elshafee, A.A. and Sh. A. M. El Tantawy \\ Agric. Extension and Rural development Research Institute. A.R.C
}

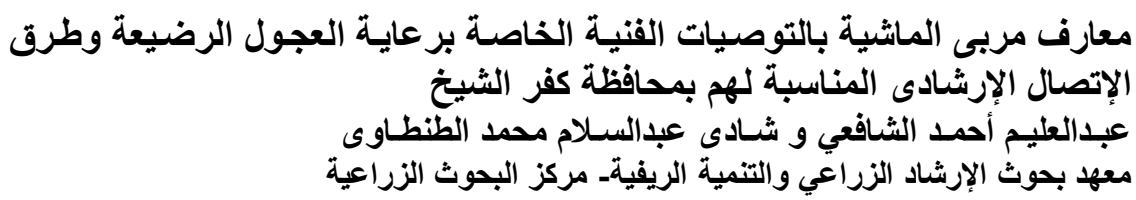

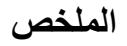

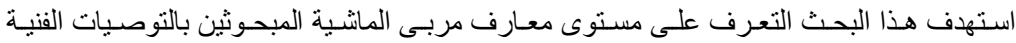

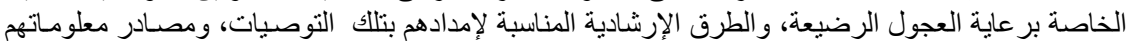

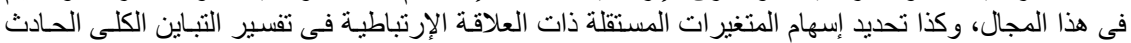

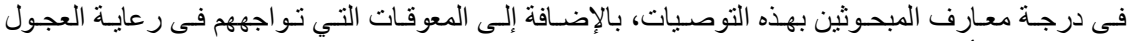

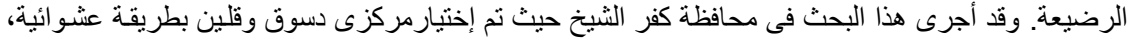

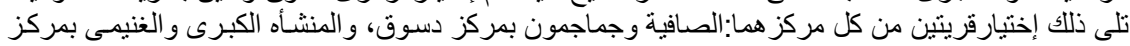

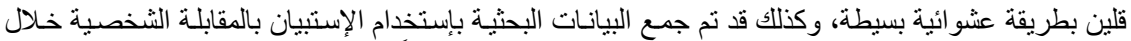

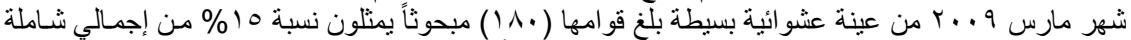

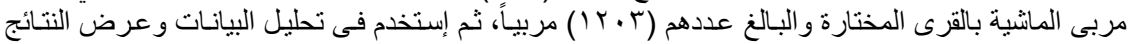

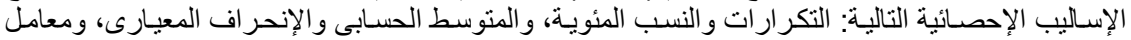

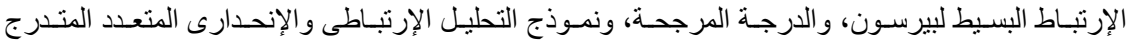

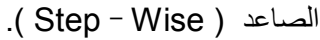

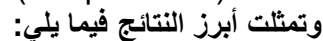

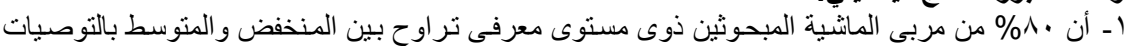
ا بالفنية الخاصة بر عاية العجول الرضيعة.

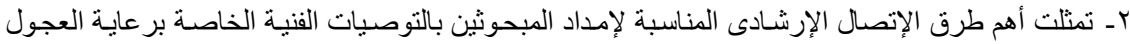

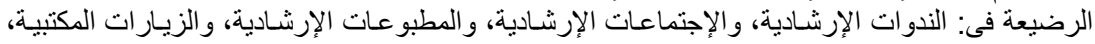

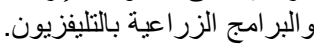
rــ كانت أبرز مصادر المعلومات التئية يستمد منها المبحوثون معارفهم فى هذا المجال هي: الطبيب البيطرى، و والأهل والأقارب، و الجير ان وان والأصدقاء.

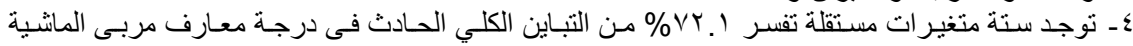

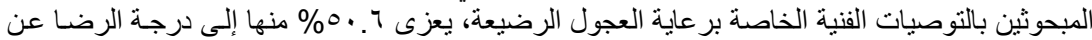

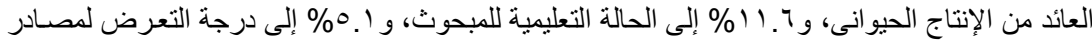

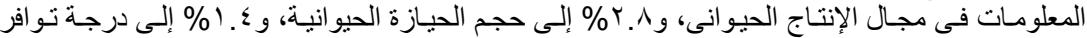

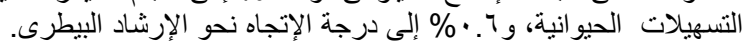

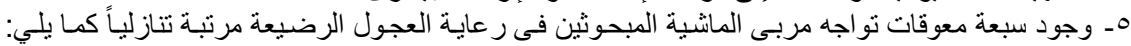

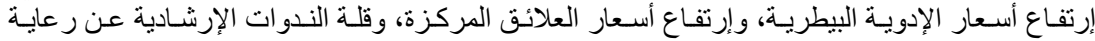

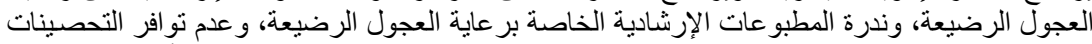

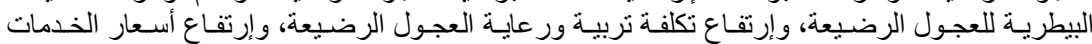




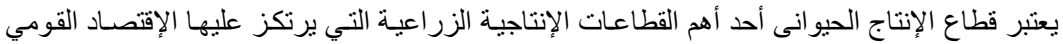

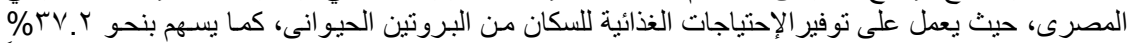

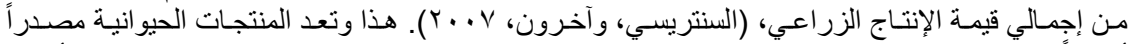

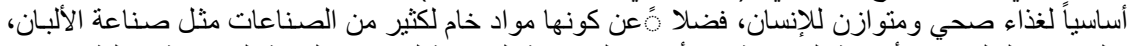

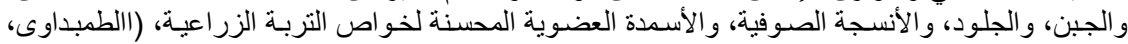
(r...

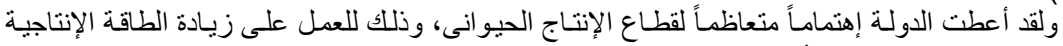

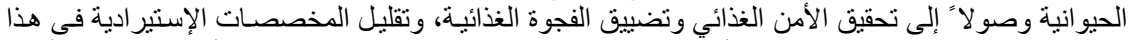

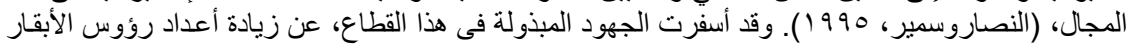

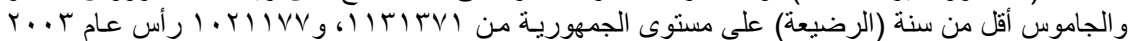

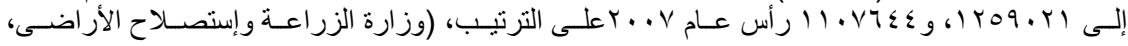

. (Y... A-r...

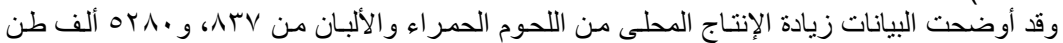

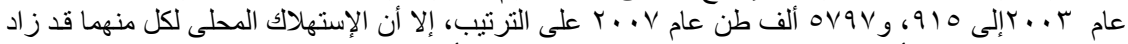

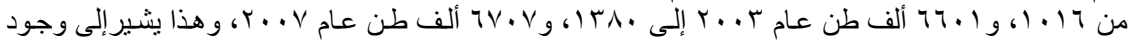

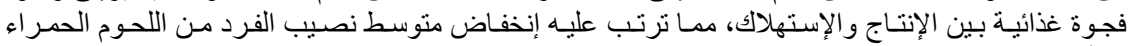

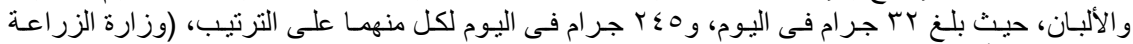

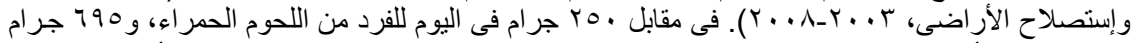

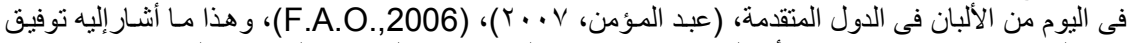

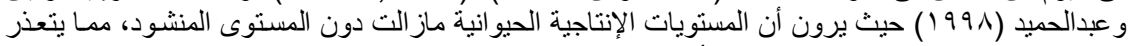

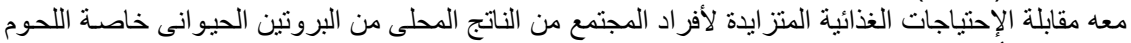

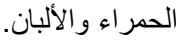

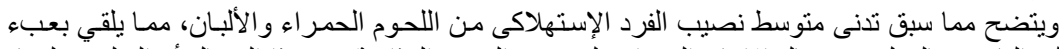

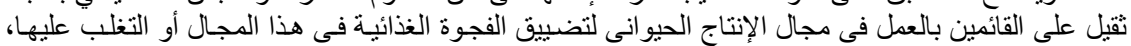

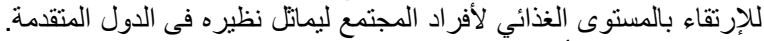

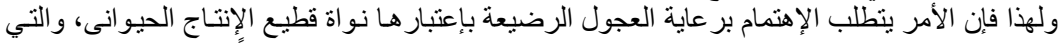

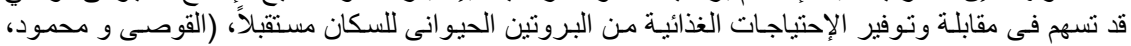

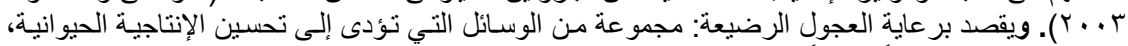

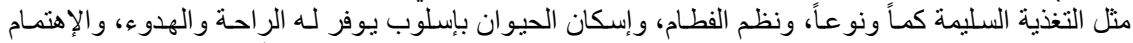

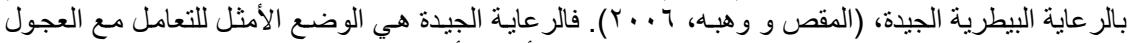

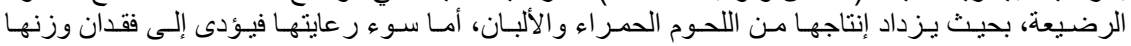

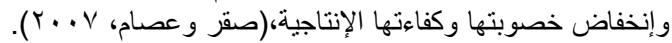

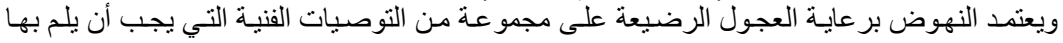

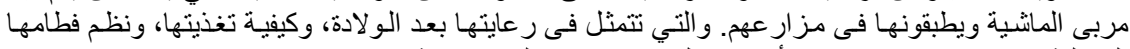

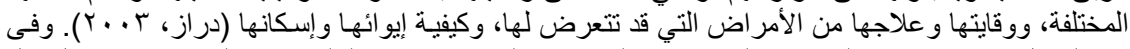

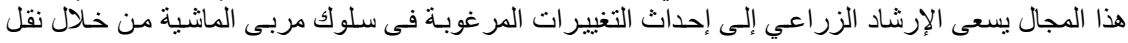

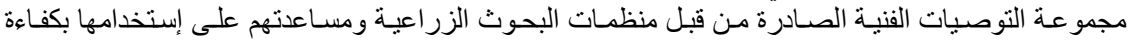

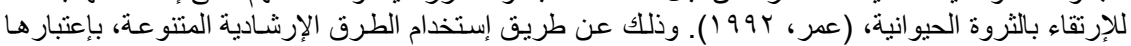

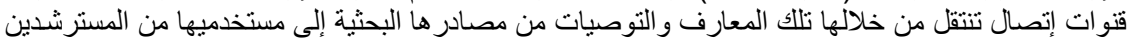

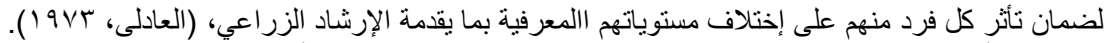

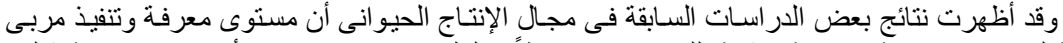

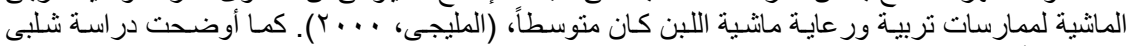

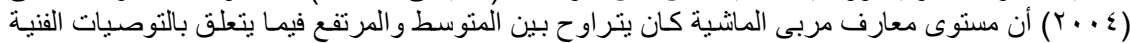

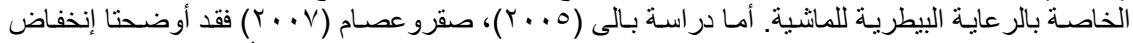

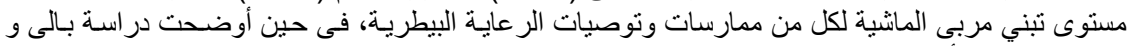

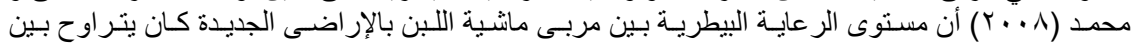




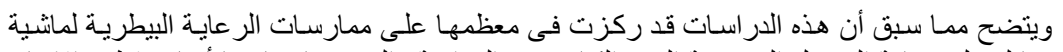

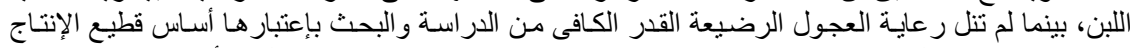

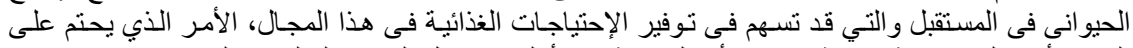

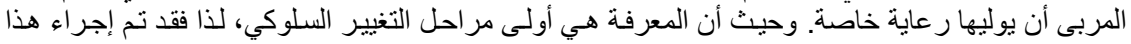

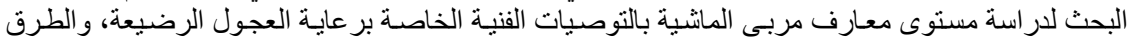

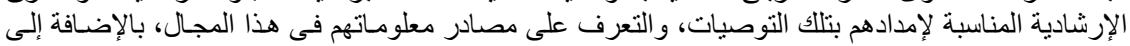

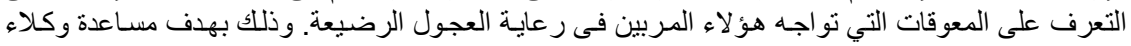

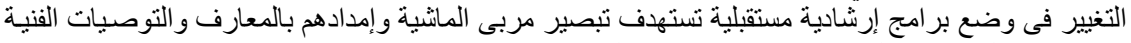

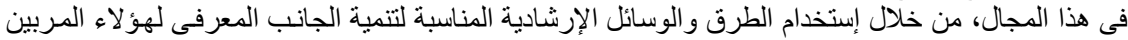

اللانهوض بالإنتاجية الحيو انية خلية.

الأهداف البحثية

يستهدف هذا البحث تحقيق الأهداف البحثية التالية:

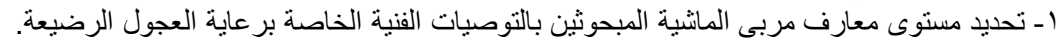

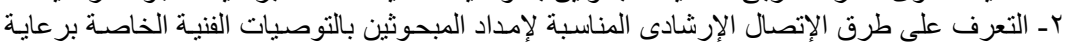
العجول الرضيعة.

r- التعرف على مصادر المعلومات التي يستمد منها المبحوثين معارفهم فيى هذا المجال.

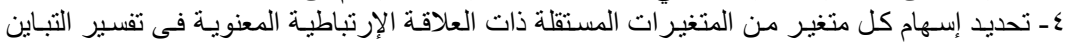

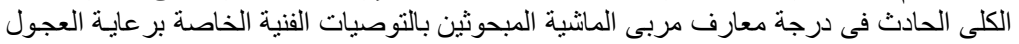

الرضيعة.

هـ التعرف على المعوقات التي تواجه مربى الماثية المبحوثين فى رعاية العجول الرضيعة. الفروض البحثية

التحقيق هدف البحث الرغة البع تم صياغة الفروض البحثية التالية:

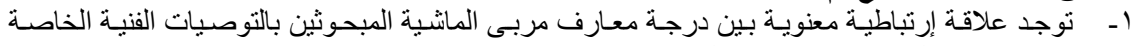

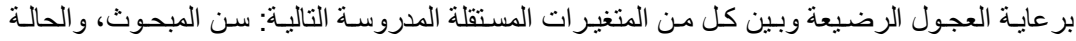

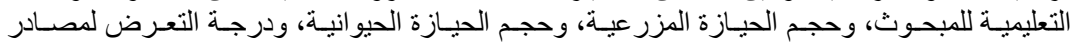

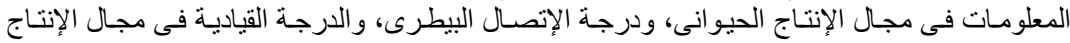

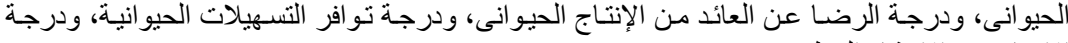
الإتجاه نحو الإرشاد البيطرى الرئ.

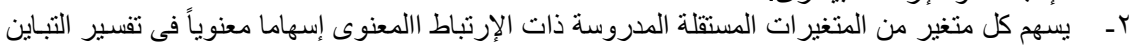

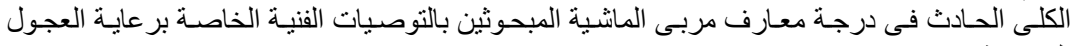
الرضيعة. وقد تم إختبار هذين الفرضين فى صورتهما الصفرية

\section{الطريقة البحثية}

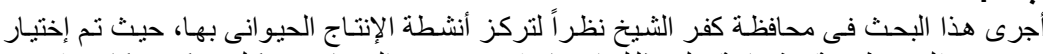

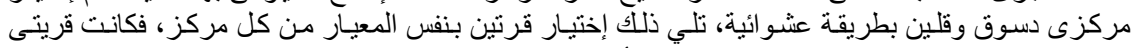

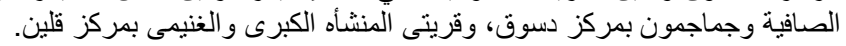

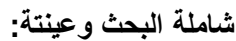

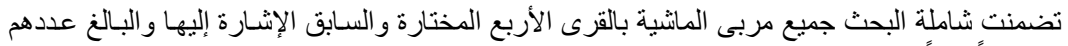

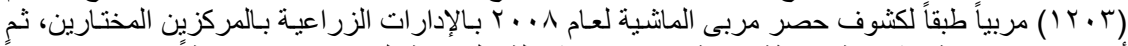

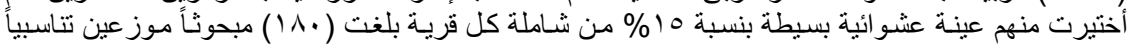

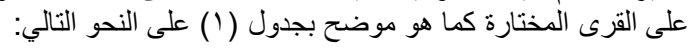

جدول ( ) : توزيع شاملة البحث وعينتة على القرى المختارة بالمراكز موضع الدراسة 


\section{Elshafee, A.A. and Sh. A. M. El Tantawy}

\begin{tabular}{|c|c|c|c|c|c|}
\hline \multirow{2}{*}{ الإجمالي } & \multicolumn{2}{|c|}{ قلين } & \multicolumn{2}{|c|}{ دسوق } & المراكز \\
\hline & الغنيمى & المنشأه الكبرى & جماجمون & الصافية & القرى المختارة \\
\hline$M \cdot r$ & $r \wedge \neg$ & $0 \leq Y$ & 110 & 19. & شاملة مربي الماشية \\
\hline $1 \wedge$ & $\varepsilon r$ & 11 & $r \wedge$ & $r \wedge$ & عينة البحث \\
\hline
\end{tabular}

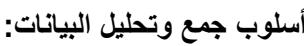

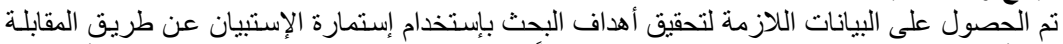

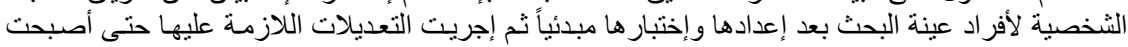

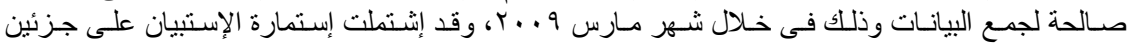

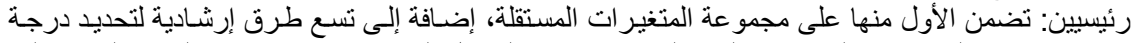

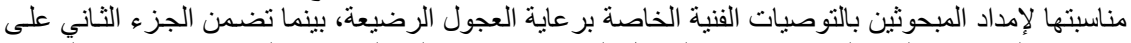

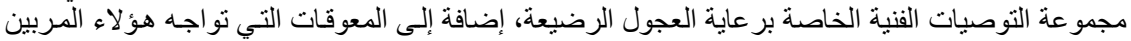

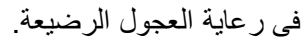

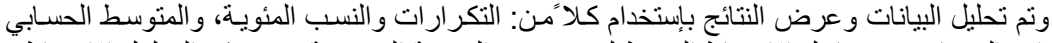

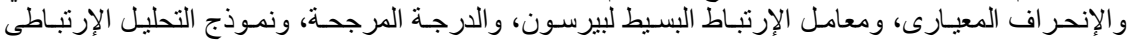

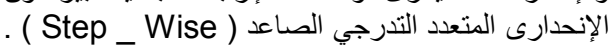

التعاريف إلاجرائية للمتغيرات البحثية وكيفية قيَّسها:

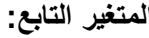

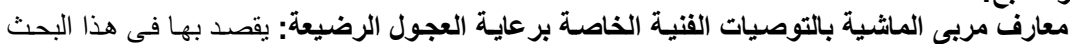

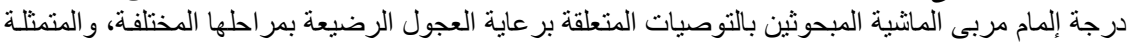

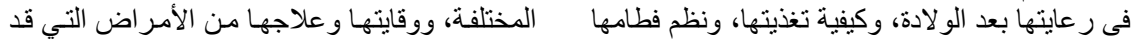

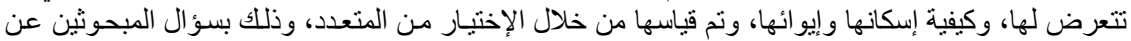

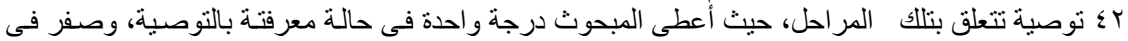

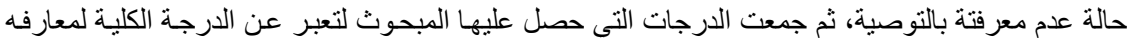

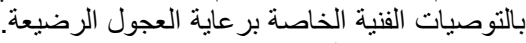

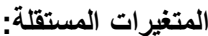
ا-سنن المبحوث: يقصد به سن المبحوث وقت جمع البيانات البحثية، وتم التعبير عنه بعدد السنوات لأقرب سنة

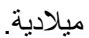

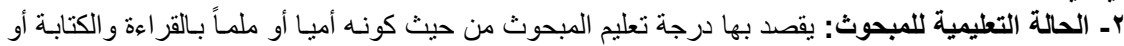

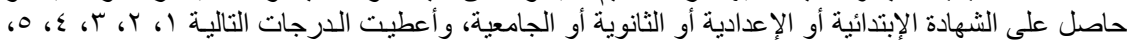

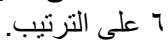
rا بـ حجم الحيازة المزرعية: بقصد بها إجمالي الحيازة الزراعية التي بمثلكها المبحوث ويمارس فهها نثاطه

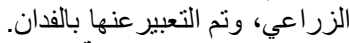

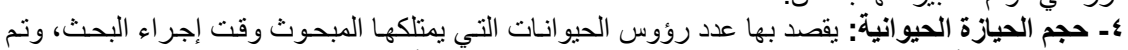

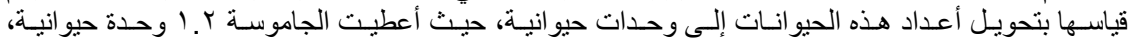

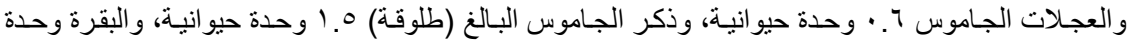

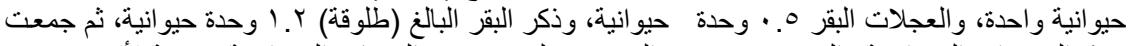

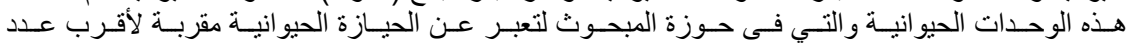

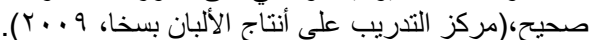

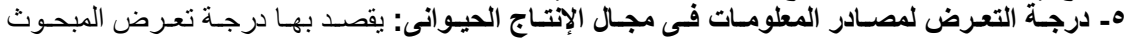

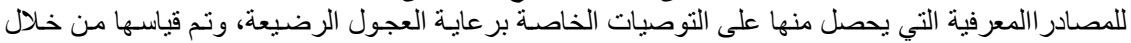

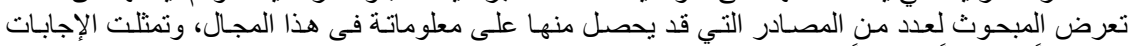

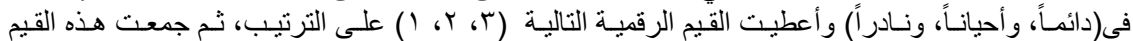

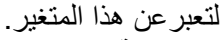

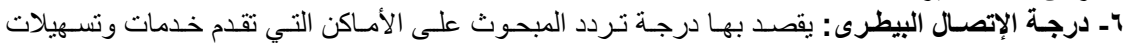

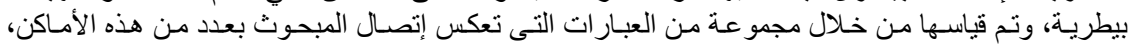




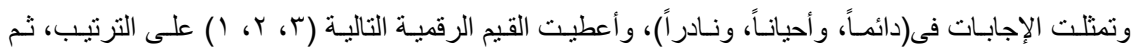

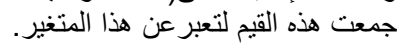

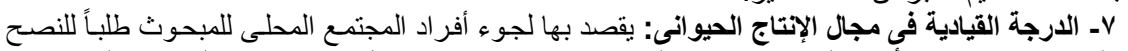

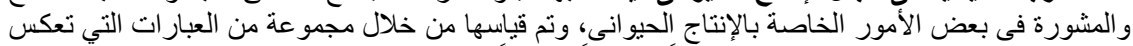

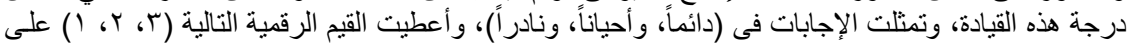

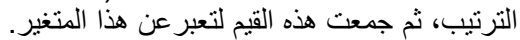

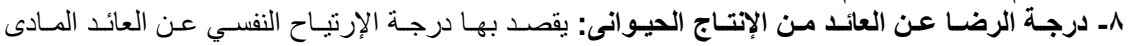

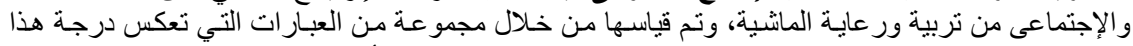

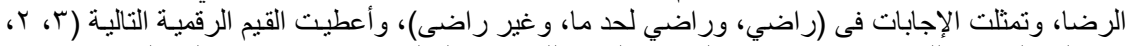

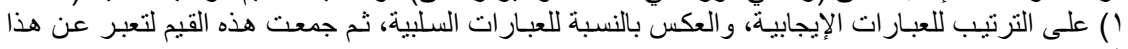

المتغير.

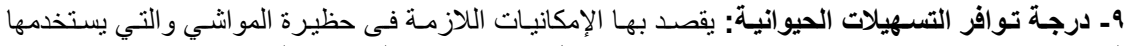

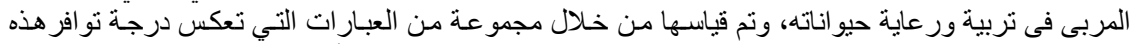

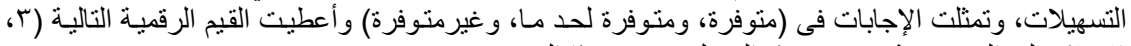

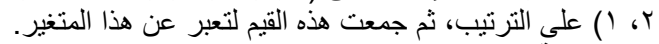

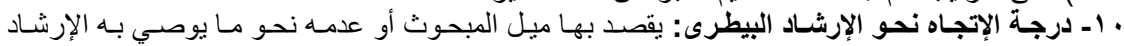

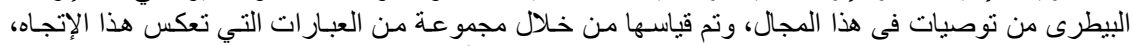

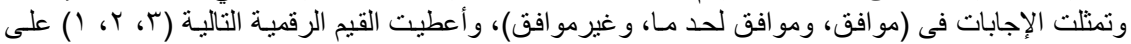

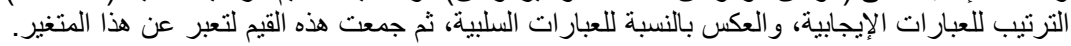

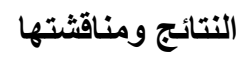

أولاً: مستوى معارف مربى الماشية المبحوثين بالتوصيات الفنية الخاصة برعاية العجول الرضيعة:

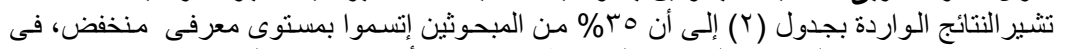

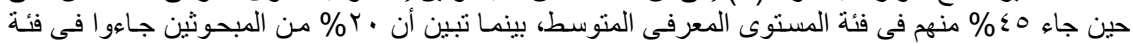

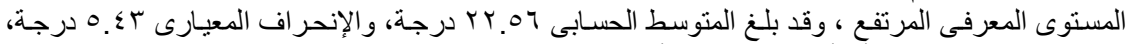

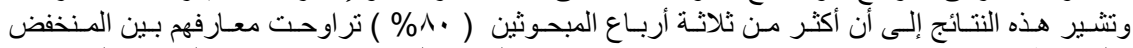

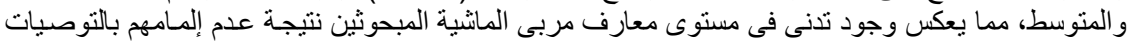

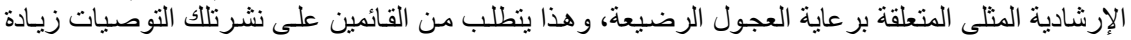

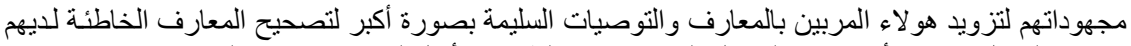

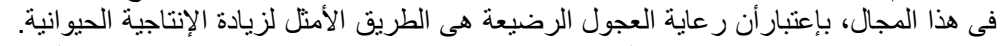

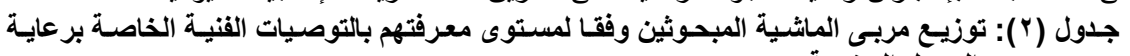

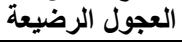

\begin{tabular}{|c|c|c|}
\hline$\%$ & عدد & فئات المستوى المعرفى \\
\hline ro.. & IT & منخفض(Y Y - 9 (1) ) درجة \\
\hline$\leqslant 0$. & $\wedge 1$ & متوسط (·• - F r ) درجة \\
\hline$r \cdot . \cdot$ & rq & 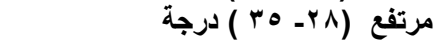 \\
\hline $1 \ldots$ & 11. & المجموع \\
\hline
\end{tabular}

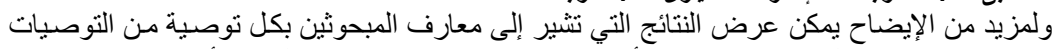

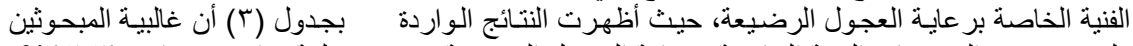

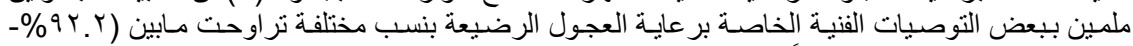

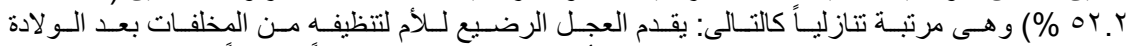

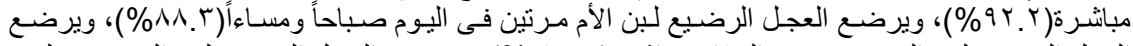

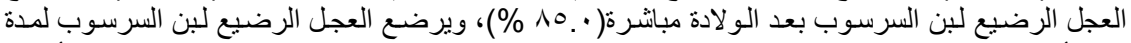

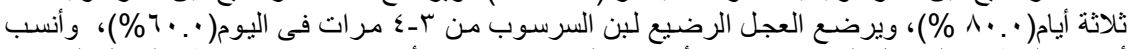

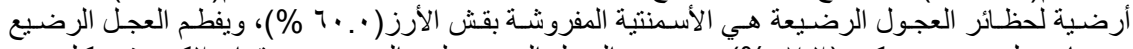

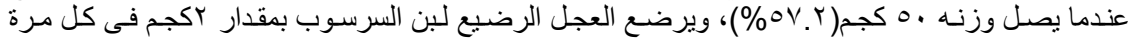




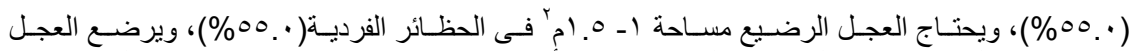

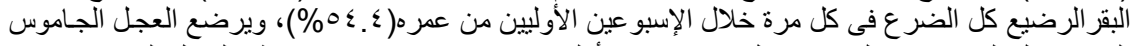

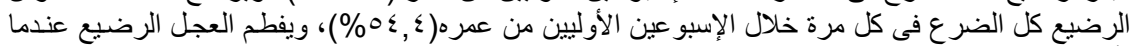

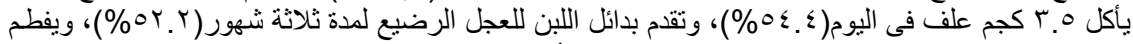

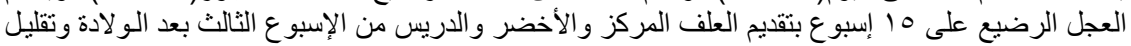

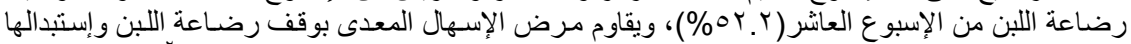

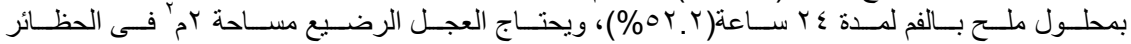

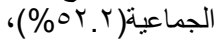

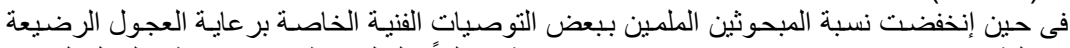

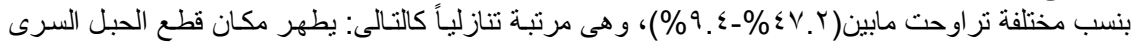

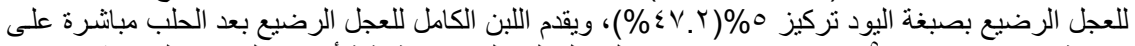

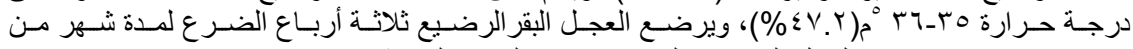

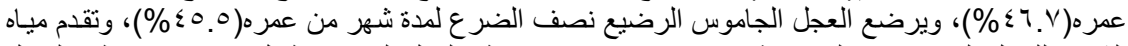

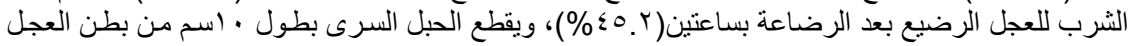

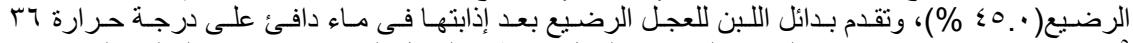

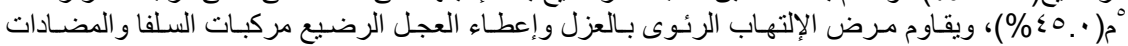

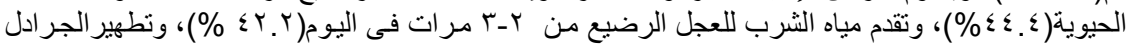

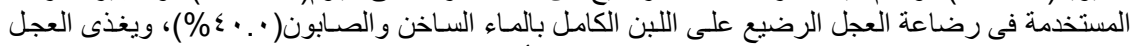

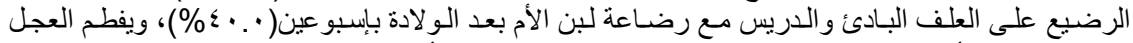

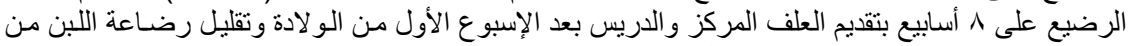

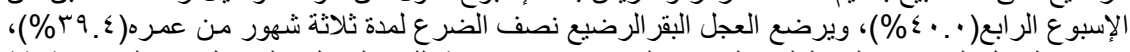

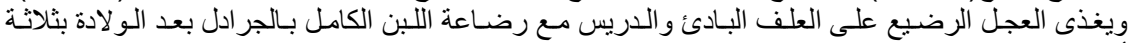

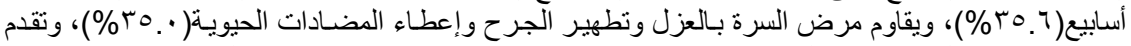

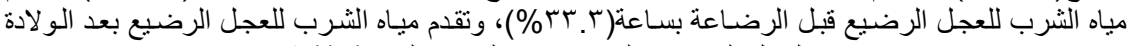

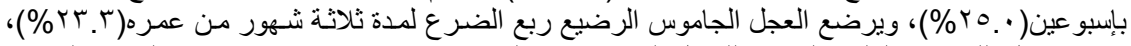

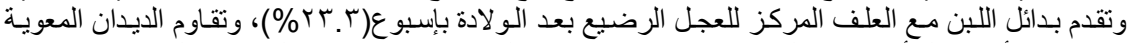

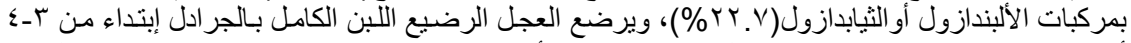

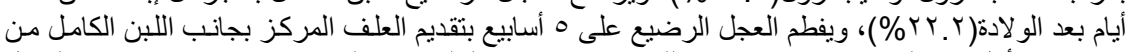

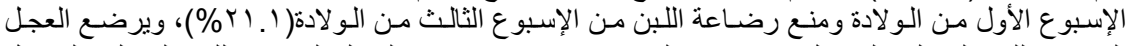

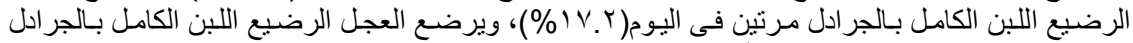

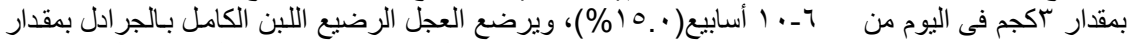

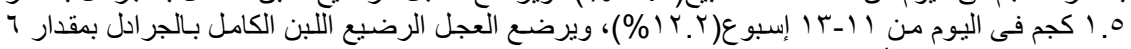

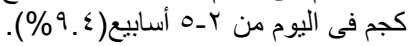

جدول (r): توزيع مربى الماثية المبحوثين وفقاً لمعرفتهم بكل توصية من التوصيات الفتية الخاصـة برعاية العجول الرضيعة المرية

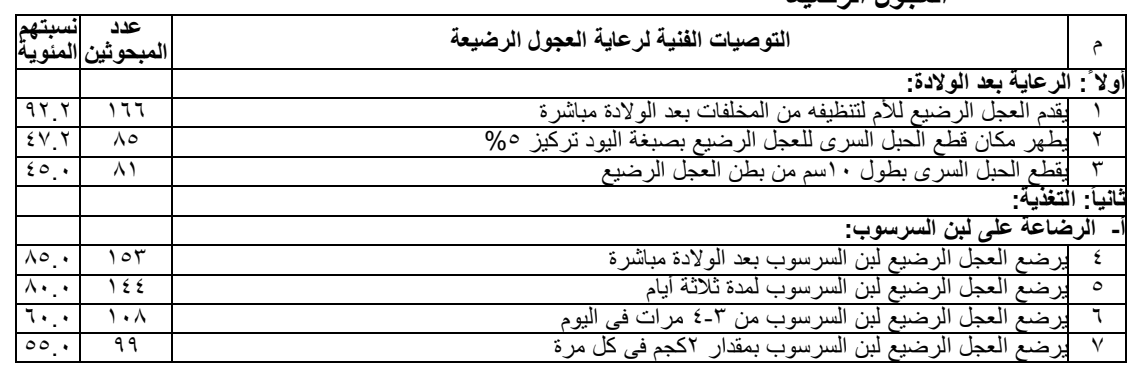




\section{J. Agric. Sci. Mansoura Univ., 34 (10), October, 2009}

\begin{tabular}{|c|c|c|}
\hline & & ب - الرضاعة الطبيعية (لبن الام الكامل): \\
\hline$\Lambda \Lambda . \Gamma$ & 109 & ^ إبرضع العجل الرضيع لبن الأم مرتين فى اليوم صباحا ومساء| \\
\hline $0 \leqslant . \leqslant$ & 91 & ايرضع العجل البقر الرضيع كل الضرع فى كل مرة خلال الإسبو عين الأوليين من عمره \\
\hline $0 \leqslant . \varepsilon$ & 91 & ابرضع العجل الجاموس الرضيع كل الضرع فى كل مرة خلال الإسبو عين الاوليين من عمره \\
\hline$\sum 7 . \mathrm{V}$ & $\Lambda \varepsilon$ & ايرضع العجل البقر الرضيع ثلاثة أرباع الضرع لمدة شهر من عمره \\
\hline$\leqslant 0.0$ & AT & ابرضع العجل الجاموس الرضيع نصف الضرع لمدة شهر من عمره \\
\hline rq. & V) & برضع العجل البقر الرضيع نصف الضر ع لمدة ثلاثة شهور من عمره \\
\hline \multirow[t]{2}{*}{ rt.r } & $\sum Y$ & ايرضع العجل الجاموس الرضيع ربع الضر ع لمدة ثلاثة شهور من عمره \\
\hline & & ج - الرضاعة الصناعية: \\
\hline \&V.Y & No & 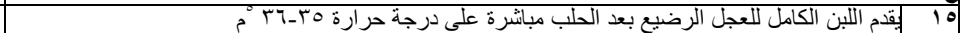 \\
\hline$\leqslant 0 . Y$ & $\Lambda 1$ & تققدم مياه الشرب للعجل الرضيع بعد الرضاعة بساعتين \\
\hline$\sum Y . Y$ & $\sqrt{74}$ & IV تقدم مياه الثرب للعجل الرضيع من Y-r مر ات فى اليوم \\
\hline$\varepsilon \cdot . \cdot$ & VY & تطهير الجر ادل المستخدمة فى رضاعة العجل الرضيع على اللبن الكامل بالماء الساخن والصابون \\
\hline rr.r & 7. & 19 اتقدم مباه الثرب للعجل الرضيع قبل الرضاعة بساعة \\
\hline ro.. & $\leqslant 0$ & تقدم مياه الشرب للعجل الرضيع بعد الو لادة بإسبو عين \\
\hline YY.Y & $\varepsilon$. & ا Y برضع العجل الرضيع اللبن الكامل بالجر ادل إبتداء من بـــ أبام بعد الو لادة \\
\hline TV.Y & TI & r r برضع العجل الرضيع اللبن الكامل بالجر ادل مرتين فى اليوم \\
\hline 10.0 & TV & 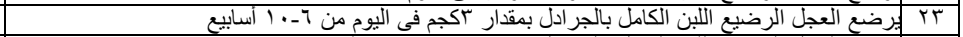 \\
\hline IY.Y & rt & 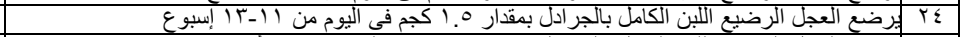 \\
\hline \multirow[t]{2}{*}{9.5} & IV & 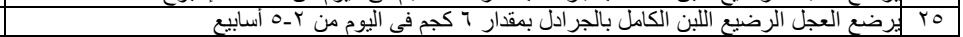 \\
\hline & & دـ ـ التغذية على بدائل اللبن والعلف المركز: \\
\hline OY.Y & $9 \varepsilon$ & جr بتقدم بدائل اللبن للعجل الرضيع لمدة ثلاثة شهور \\
\hline \&0.. & $\Lambda 1$ & FV تقام بدائل اللبن للعجل الرضيع بعد إذابتها فى ماء دافئ على درجة حر ارة ب؟ م \\
\hline$\varepsilon \cdot . \cdot$ & VY & 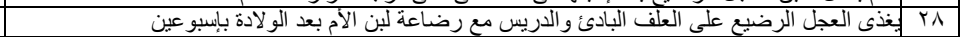 \\
\hline$r 0.7$ & $7 \varepsilon$ & qو ب بذذى العجل الرضيع على العلف البادئ والدريس مع رضاعة اللبن الكامل بالجر ادل بعد الو لادة بثلاثة أسابيع \\
\hline \multirow[t]{2}{*}{ YT.r } & $\varepsilon r$ & ثقدم بدائل اللبن مع العلف المركز للعجل الرضيع بعد الو لادة بإسبوع \\
\hline & & الفطام: \\
\hline$O V_{.1}$ & 1.4 & آ بفظم العجل الرضيع عندما بصل وزنه ،0 كجم \\
\hline $0 \leqslant . \varepsilon$ & 91 & بr بيطم العجل الرضيع عندما يأكل 0.r كجم علف في اليوم \\
\hline Or.Y & $9 \varepsilon$ & 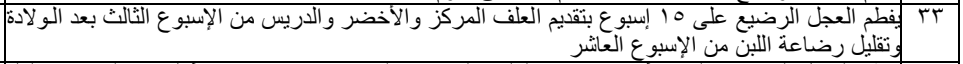 \\
\hline$\varepsilon \cdot \cdot$ & VT & 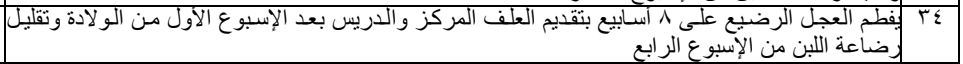 \\
\hline \multirow[t]{2}{*}{ YI.1 } & $T \Lambda$ & 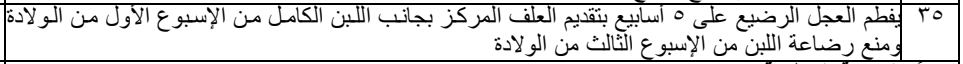 \\
\hline & & رابعا: الرعايةً البيطرية: \\
\hline or.Y & $9 \varepsilon$ & Tr ب بقاو مرض الإسهال المعدى بوقف رضاعة اللبن و إنتبدالها بمحلول ملح بالفم لمدة ؟Y ساعة \\
\hline$\varepsilon \varepsilon . \varepsilon$ & $\Lambda$. & VV يقاوم مرض الإلتهاب الرئوى بالعزل و إعطاء العجل الرضيع مركبات السلفا والمضادات الحيوية \\
\hline ro.. & 74 & 1T يقاوم مرض السرة بالعزل وتطهير الجرح و إعطاء المضادات الحيوية \\
\hline \multirow[t]{2}{*}{ YY. } & छ) & تقاوم الديدان المعوية بمركبات الألبندازول أو الثيابدازول \\
\hline & & خامسا: الإيواء: \\
\hline $7 \cdot$. & $1 \cdot 1$ & •_|أنسب أرضبة لحظائر العجول الرضبعة هي الأسمنتية المفروشة بقش الأرز \\
\hline 00. & 99 & بحتاج العجل الرضيع مساحة ( ــ. ام' في الحظائر الفردية \\
\hline Or.Y & $9 \varepsilon$ & بحتاج العجل الرضيع مساحة بم' فى الحظّائر الجماعية \\
\hline
\end{tabular}

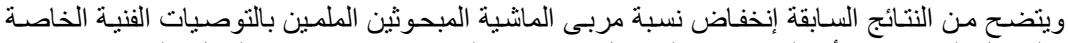

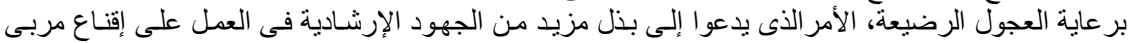

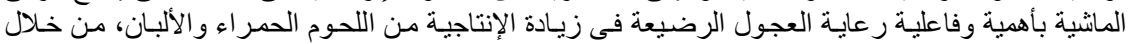

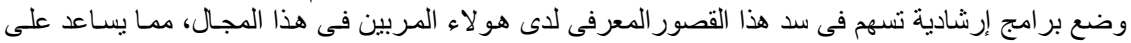

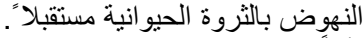

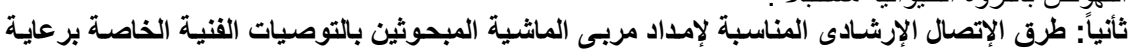

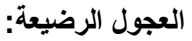

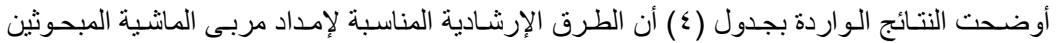

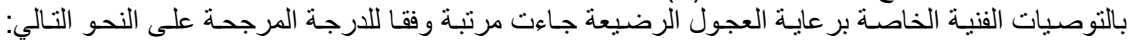

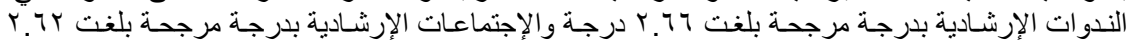

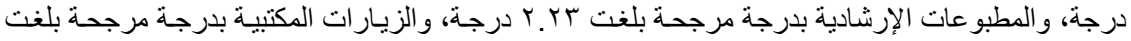

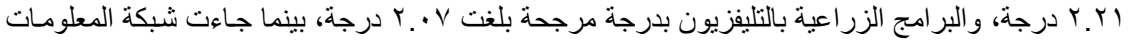


Elshafee, A.A. and Sh. A. M. El Tantawy

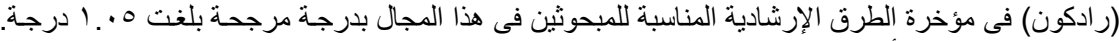

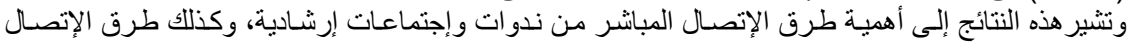

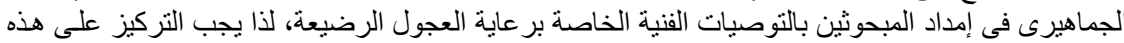

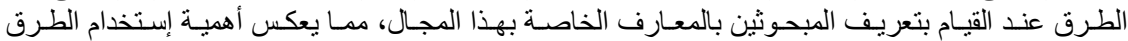
الإرشادية فى العمل الإرشادى.

جدول ( ) : ترتيب طرق الإتصـال الإرشـادى المناسبة لإمـاد مربسى الماشية المبحوثين بالتوصيات القتية

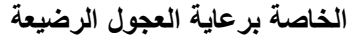

\begin{tabular}{|c|c|c|}
\hline الارجة المرجحة & الطرق الإرشادية & م \\
\hline Y.77 & الندوات الإرشادية & 1 \\
\hline Y.TY & الإجتماعات الإرشادية & $r$ \\
\hline T.YT & المطبو عات الإرشادية & $r$ \\
\hline Y.YI & الزيار ات المكتبية & $\varepsilon$ \\
\hline$r . \cdot V$ & البر امج الزراعية بالتليفزيون & 0 \\
\hline 1.01 & الزيار ات المنزلية & 7 \\
\hline $1.0 \mathrm{~V}$ & الملصقات الإرشادية & V \\
\hline $1 . \leqslant 1$ & البر امج الزراعية بالر اديو & $\wedge$ \\
\hline 1.0 & شبكة المعلومات (رادكون) & 9 \\
\hline
\end{tabular}

ثالثاً: مصـادر المعلومـات التي يستمد منها مربس الماثـية المبحوثين معارفهم فى مجـال رعايـة العجول

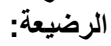

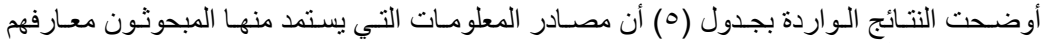

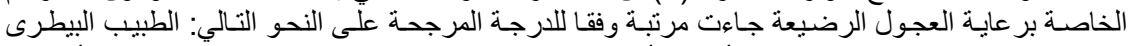

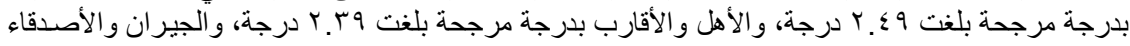

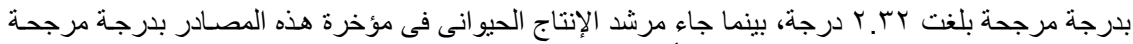

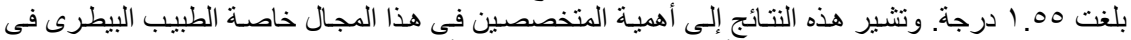

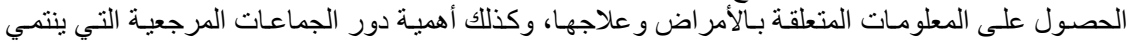

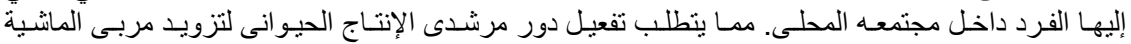

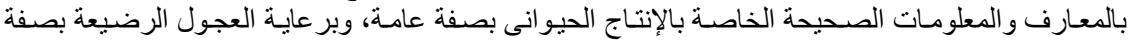

خاصة.

جدول (•): ترتيب مصادر المعلومات التي يستمد منها مربى الماشية المبحوثين معارفهم فى مجال رعاية

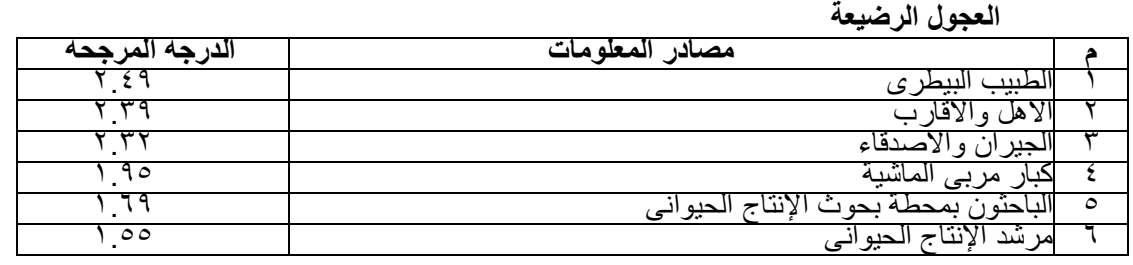

رابعاً: إسهام المتغيرات المستقلة ذات العلاقة الإرتباطية المعنوية فى تفسير التباين الكلي الحادث فى درجة

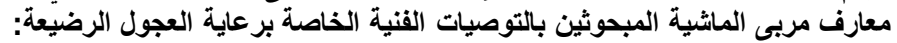

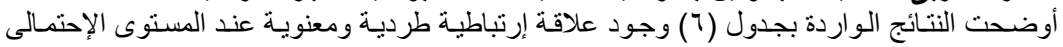

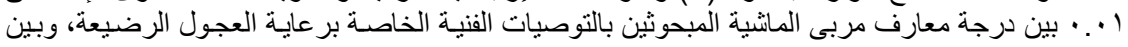




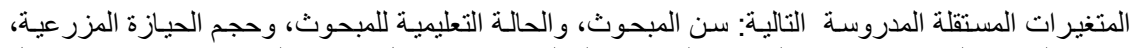

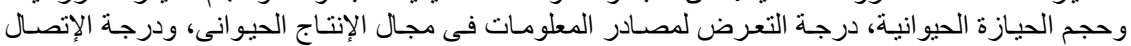

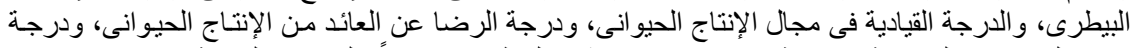

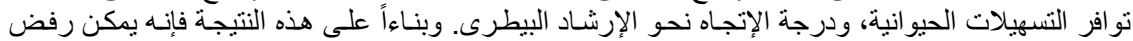
الفرض الإحصائى الأول وقبول الفرد الفرض البديل.

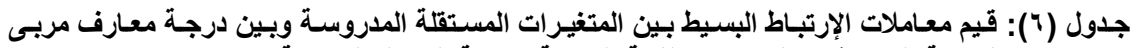

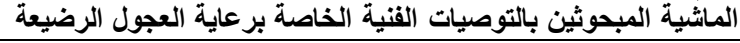

\begin{tabular}{|c|c|c|}
\hline معامل الإرثباط & المتغيرات المستقلة & r \\
\hline$\because$ TIT & سن المبحوث & 1 \\
\hline .010 & الحالة التعليمية للمبحوث & $T$ \\
\hline .519 & حجم الحيازة المزرعية & $\Gamma$ \\
\hline $.01 \cdot$ & حجم الحيازة الحيوانية & $\varepsilon$ \\
\hline .090 & لدرجة التعرض لمصادر المعلومات في مجال الإنتاج الحيو انى & 0 \\
\hline$\because \leqslant 79$ & لدرجة الإتصال البيطرى ع & 7 \\
\hline. $\mathrm{MTV}$ & |الدرجة الفيادية في مجال الإنتاج الحيو انى & V \\
\hline$\because V I$ & ترجة الرضا عن العائد من الإنتاج الحيوانى & $\Lambda$ \\
\hline .0 .0 & |ررجة تو افر التسهيلات الحيو انية & 9 \\
\hline.$r 99$ & ترجة الإتجاه نحو الإرشاد البيطرى & $1 \cdot$ \\
\hline
\end{tabular}

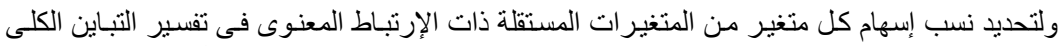

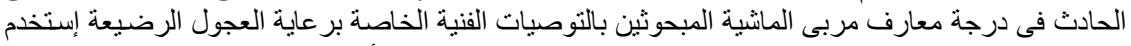

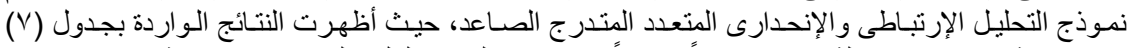

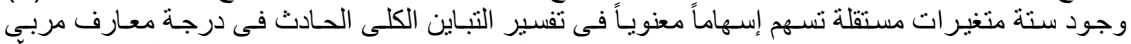

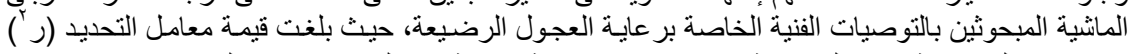

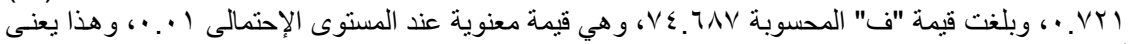

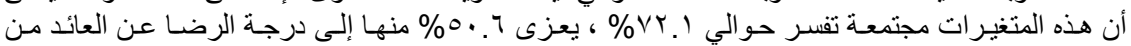

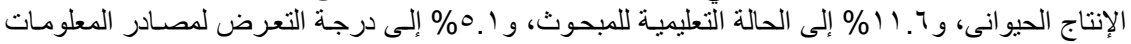

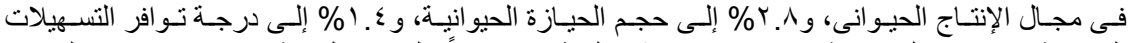

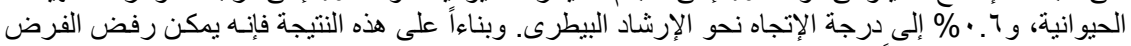

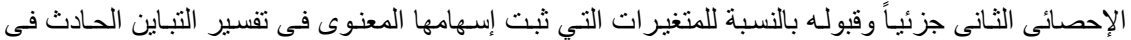

$$
\text { المتغير التابع. }
$$

جدول (V): نموذج مختزل للعلاقة بين المتغيرات المستقلة المدروسـة وبين درجة معارف مربـى الماثية

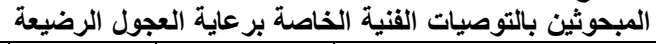

\begin{tabular}{|c|c|c|c|c|c|}
\hline | اللتباين المفسير |لمئة & |للتباينة المفسر اكمية & قيمة (ت) & معامل الإنحدار & المتغيرات المستقلة & م \\
\hline 0.7 & .0 .7 & ** $9.1 \%$ & $\cdot\{Y \mid$ & 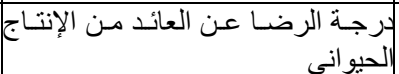 & 1 \\
\hline 11.7 & . TYY & $\varepsilon .09$ & .87 & |الحالة التعليمية للمبحوث & $r$ \\
\hline 0.1 &. $.7 V T$ & $r . \wedge$ &..$Y 71$ & درجة التعرض لمصادر المعلومات & $r$ \\
\hline T.A & $\cdot v \cdot 1$ & r. .99 & . YYO & حجم الحيازة الحيو انية & $\xi$ \\
\hline $1 . \varepsilon$ & .210 & T.A. & $\cdot .111$ & لدرجة تو افر التسهيلات الحيو انية & 0 \\
\hline$\cdot .7$ &.$V Y I$ & T.V & .111 & ثرجة الإتجاه نحو الإرشاد البيطرى & 7 \\
\hline
\end{tabular}


Elshafee, A.A. and Sh. A. M. El Tantawy

خامسا: معوقات رعاية العجول الرضيعة من وجهة نظر مربى الماشية المبحوثين:

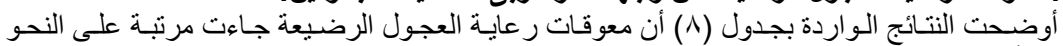

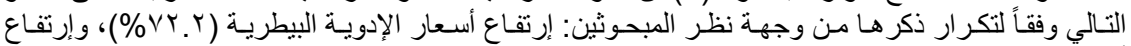

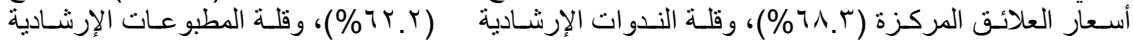

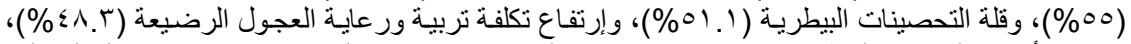

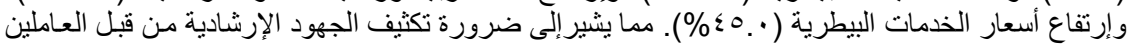

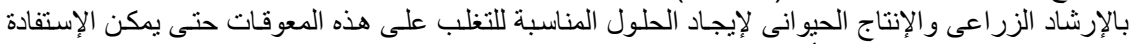

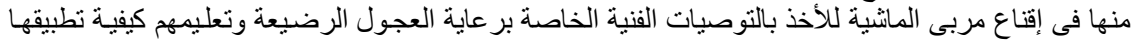

أملاُفى الإرتقاء بمستوى إنتاجيتها.

جدول (^): معوقات رعاية العجول الرضيعة من وجهة نظر مربي الماثية المبحوثين

\begin{tabular}{|c|c|c|c|}
\hline \multicolumn{2}{|c|}{ التكرارات } & \multirow{2}{*}{ المعوقات } & \multirow[t]{2}{*}{ م } \\
\hline$\%$ & عدد & & \\
\hline 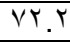 & $\pi+$ & | إرتفاع أسعار الإدوية البيطرية & 1 \\
\hline $7 \Lambda . \Gamma$ & TrT & إرتفاع أسعار العلائق المركزة & r \\
\hline 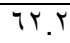 & IIr & قلمة الندوات الإرشادية عن رعاية العجول الرضيعة & r \\
\hline 00. & 99 & لتلة المطبو عات الإرشادية فى هذا المجال & $\varepsilon$ \\
\hline 01.1 & QT & لقلمة التحصينات البيطرية للعجول الرضيعة & o \\
\hline$\varepsilon \Lambda_{\text {. }}$ & NV & |إرتفاع تكلفة تربية ور عاية العجول الرضيعة & 7 \\
\hline$\leqslant 0$. & 入I & إرتفاع أسعار الخدمات البيطرية & $\mathrm{r}$ \\
\hline
\end{tabular}

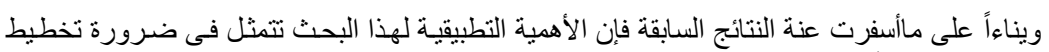

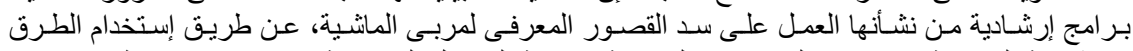

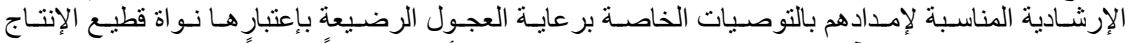

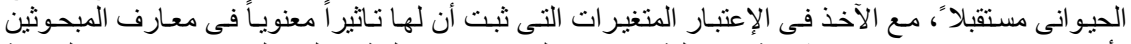

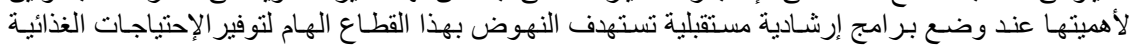

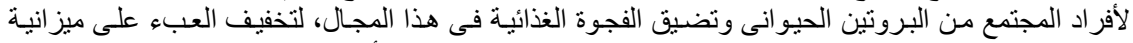

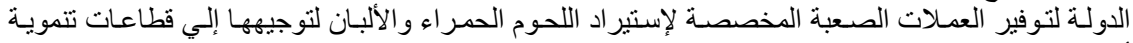

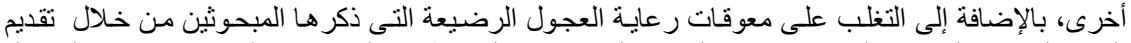

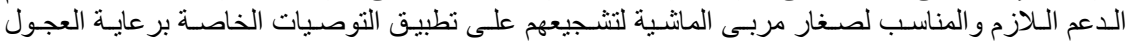
الرضيعة فى مزار عهم حنى تثؤتى الجهود الإرشادية ثمار ها فى تحقيق التنمية الزر اعية المنشودة.

\section{المراجـع}

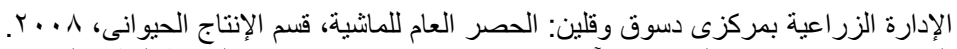

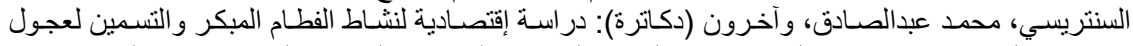

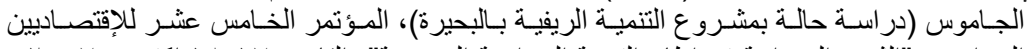

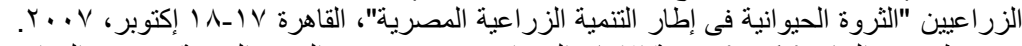

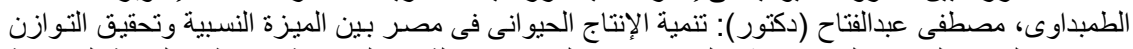

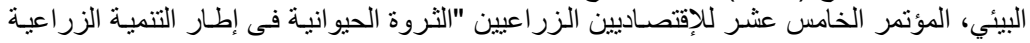

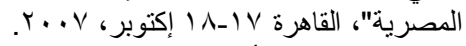

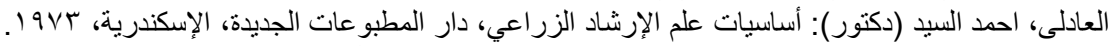

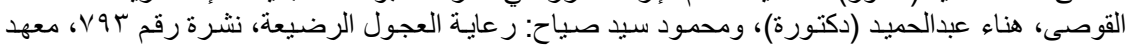

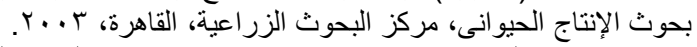

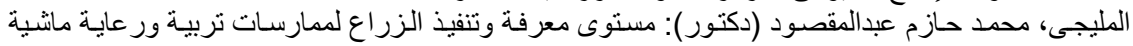

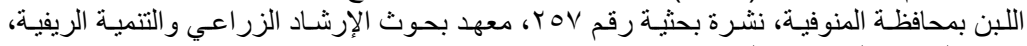

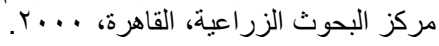




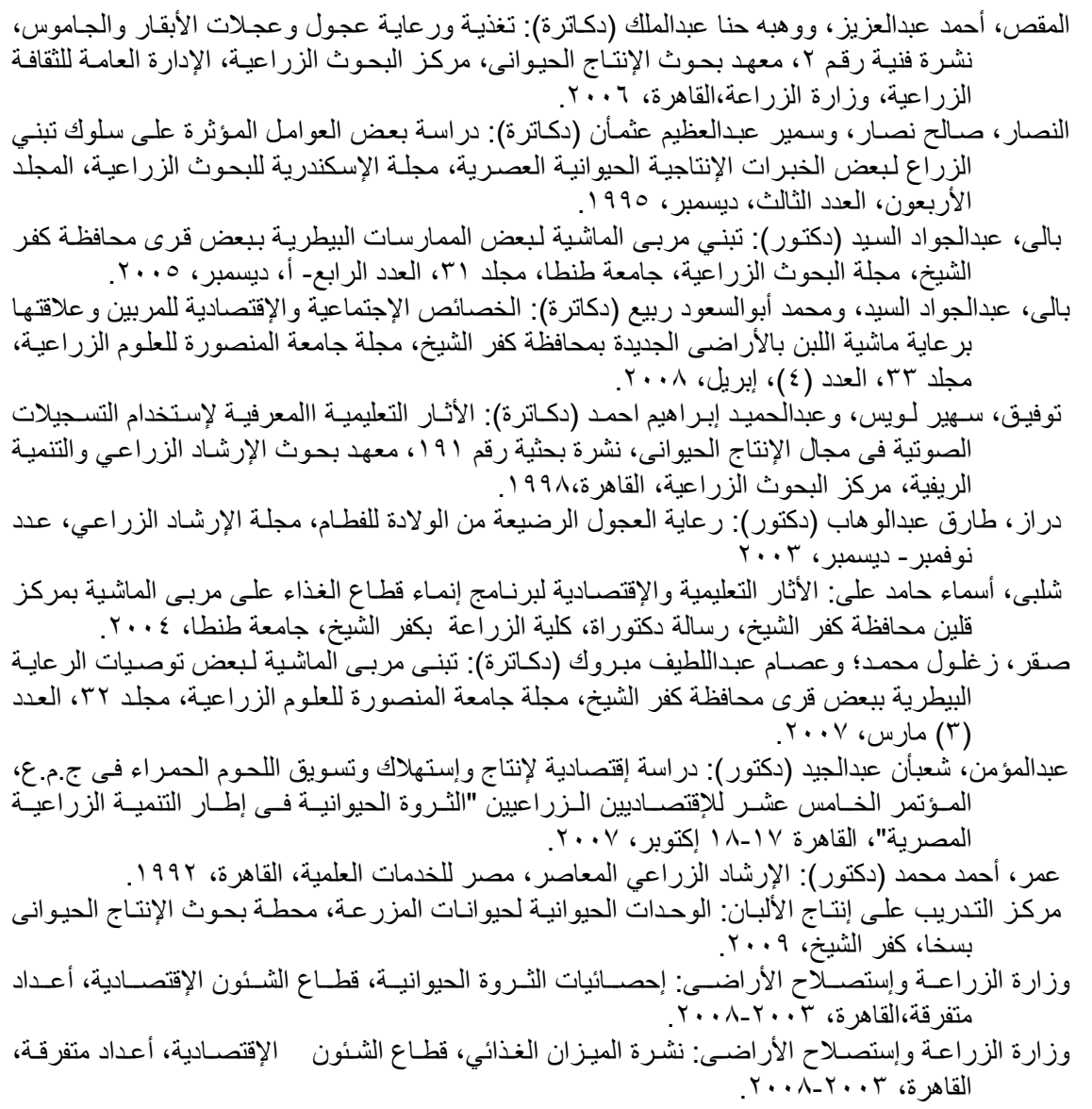

F.A.O., production year book, 2006.

\section{LIVESTOCK PRODUCERS KNOWLEDGE OF TECHNICAL RECOMMENDATIONS FOR THE CARE OF THE SUCKING CALVES AND APPROPRIATE EXTENSION COMMUNICATION METHODS FOR THEM IN KAFRELSHEIKH GOVERNORATE \\ Elshafee, A. A. and S. A. M. ELTntawy \\ Agric. Extension and Rural development Research Institute. A.R.C}

\section{ABSTRACT}

The objectives of the research were; To identify the level livestock Prodcecers Knowledge of technical recommendations for the care of the 
sucking calves, appropriate extension methods to provide them with these recommendation, sources for knowledge in this area, and determining the independent variables correlated and responsible for explanation the variation in the degree of knowledge of those respondents, in addition to identify the constraints facing them in the care of sucking calves in some villages in KafrElsheikh governorate.

The research was conducted in KafrElsheikh governorate in two districts were chosen randomly,they ane Desouk and Kaleen districts and frome each district two villages were chosen randomly also, as Ronows : EL- Safia \& Gamagmoon villages from Desouk district and Almanshah Alkopprah and Alghonemy from Kaleen district. Research data were collected using the questionnaire by personal interview during the month of March 2009 from the random sample amounted to 180 respondents represents $15 \%$ of the total (1230) livestock Prodcecers in the villages selected above.

Percentages, arithmetic mean, standard deviation, simple correlation coefficient, weighted- degree, model of multi- regression analysis (step- wise) in addition to frequencies, were used in the analysis of the data and display the results. 


\section{The most significant Results are as follows:}

$1-80 \%$ of livestock Prodcecers (respondents) have levels of knowledge between low-and medium of the technical recommendations for the care of the sucking calves.

2- the most important appropriate extension methods of the respondents to provide them with these recommendations are: extension panels, extension meeting, extension publications, office visits, and agricultural programs in T.V.

3- The most significant sources of information that provide the respondents of these recommendations are veterinarian, parents and relatives, neighbors and friends.

4- There are six independent variables together explain $72.1 \%$ of the total variation in the degree livestock breeders respondent Knowledge of technical recommendations for the care of the sucking calves, $50.6 \%$ of this variation were attributed to the degree of satisfaction than the return of the animal production, $11.6 \%$ attributed to the educational situation of the respondents, $5.1 \%$ attributed to the degree of exposure to information sources in the field of animal production, $2.8 \%$ attributed to the size of the animal's tenure, $1.4 \%$ attributed to the availability of animal facilities, and $0.6 \%$ attributed to the degree of attitude toward the extension veterinarian.

5- There are seven obstacles facing livestock Prodcecers (respondents) in the care of the sucking calves could be ranked from top to down as follows: high price of veterinary drugs, rising prices of concentrated food, lack of extension panels \& extension publications related to the care of sucking calves, and the scarcity of manuals for the care of the baby calves, non existing of veterinary vaccines for sucking calves, high cost of breeding and care of the sucking calves, and high prices of veterinary services. 